\title{
CRIMEN Y CASTIGO EN LA INGLATERRA DE LA REINA VICTORIA: "EL CASO DE LADY SANNOX"*
}

\author{
Mª del Carmen Rodríguez Fernández**
}

\begin{abstract}
Resumen: En este artículo se analiza "El caso de Lady Sannox" de Arthur Conan Doyle siguiendo un enfoque postestructuralista feminista. La historia está ambientada en el último tercio del reinado de la reina Victoria, una época en la que la sociedad patriarcal trataba desesperadamente de frenar los avances de las mujeres en la sociedad. Valiéndose de lo que Ellen Moers llama "gótico femenino" Doyle muestra la falta de espacios que las mujeres tenían para su articulación y la urdimbre tejida por Lord Sannox para dar una lección moral a su esposa. Su venganza es terrible porque Lady Sannox se convertirá en una mujer fragmentada/castrada que no podrá articular sus deseos.

Palabras clave: espacios victorianos, misoginia, gótico femenino, castración.
\end{abstract}

\begin{abstract}
In this paper I aim at analysing "The Case of Lady Sannox" by Arthur Conan Doyle following a poststructuralist feminist approach. The story is set in the last third of Victorian reign, a period in which patriarchal society was trying desperately to refrain the progression of women in society. By means of what Ellen Moers calls "the female Gothic" Doyle shows the lack of space women had for their articulation and the plot Lord Sannox contrives to give a moral lesson to his wife. His revenge is terrible because Lady Sannox will become a fragmented/castrated woman unable to articulate her desires in life.

Keywords: Victorian spaces, misogyny, female Gothic, castration.
\end{abstract}

"The Case of Lady Sannox" de Sir Arthur Conan Doyle, publicada en la colección Round the Red Lamp (1893), forma parte de una colección de historias que tienen como tema principal aspectos de la práctica médica que en ocasiones muestran facetas oscuras de la medicina. Este relato constituye una de estas historias macabras por su contenido y atípicas del autor por carecer de sus personajes habituales, Sherlock Holmes y el Dr. Watson. No hay en ella una pesquisa policial, pero sí hay un hecho criminal y han de ser los propios lectores, con la perspectiva histórica que confiere la distancia temporal de más de un siglo, los que se conviertan en detectives, reflexionen y juzguen el crimen cometido e indaguen cómo y por qué se propició el drama, buscando para ello el subtexto que convierte a la historia en tema de actualidad por la violencia de género y el maltrato que hay en ella.

Tzvetan Todorov analiza en "The Typology of the Detective Fiction" cómo en el género policiaco hay dos momentos a tener en cuenta, "The narrative... superimposes two temporal series: the days of the investigation which begin with the crime, and the days of

Fecha de recepción: mayo 2006

Fecha de aceptación y versión final: julio 2006

** Profesora titular, Departamento de Filología Anglogermánica y Francesa, Universidad de Oviedo; $\triangle$ maica@uniovi.es. 
the drama which lead up to it." (1988: 159). Es este análisis de los días del drama que conducen finalmente a su ejecución el que interesa en este estudio. Al carecer el texto de la investigación policial posterior, toda la curiosidad se concentra en el hecho dramático del que habla Todorov.

El paso del tiempo permite apreciar cómo una misma obra puede ofrecer diferentes puntos de partida para su análisis, según el enfoque que se adopte. Uno de estos consiste en estudiar el texto y hacer una deconstrucción del relato desde el punto de vista de género, siguiendo para ello los métodos de análisis postestructuralistas que buscan desentrañar posibles lecturas y rescatar a los personajes de la existencia de reclusión que les deparaba la moral victoriana. De acuerdo con esta perspectiva, el análisis se centra no ya en el carácter vengador de Lord Sannox y en la lección moralizante que se puede extraer de la historia para los lectores victorianos, sino en la violencia y el abuso que se comete contra su esposa. De este modo, al aplicar este enfoque, el caso de Lady Sannox que da título a la obra no es un relato en el que prima la venganza que el rencoroso y aleccionador marido inflige a su conyuge, sino que resulta ser una de las muchas historias que se podrían haber escrito acerca de cualquier mujer en el siglo XIX y que un enfoque postestructuralista permite deconstruir. Según se demostrará en este estudio, el cuerpo de Lady Sannox queda violentado, desfigurado e inarticulado para desarrollar su experiencia vital como mujer.

Como punto de partida es importante distinguir los significados de la palabra crimen, puesto que en inglés tiene unos significados más amplios que en la lengua castellana. Sabido es que en la cultura anglosajona el vocablo "crime" tiene dos acepciones relacionadas entre sí. Dice así la fuente inglesa, 1) "a crime is an illegal action for which a person can be punished by law" y 2) "an action which is morally wrong but not illegal" (Collins 1998: 335). Es decir, "crime" se refiere a una acción moralmente mala que ninguna persona tiene derecho a cometer contra otra y, por tanto, puede ser castigada por la ley. En español la palabra "crimen" se define como: "delito grave" (R.A.E. 1970: 378), o como "delito muy grave, consistente en matar o herir gravemente a alguien" (Moliner 1990: 803).

Esta diferencia de concepto en ambas lenguas, entre lo que está moralmente mal, punible o no, y lo que es delito grave conducente a la muerte, es importante para hacer este análisis, porque en el relato de Conan Doyle se perpetra un crimen que contiene esta significación amplia que tiene la acepción inglesa del término. Desde el punto de vista patriarcal, Lady Sannox es una mujer adúltera que comete un acto inmoral a los ojos de la sociedad victoriana y podría ser castigada por ello, pues con su conducta se sitúa en los márgenes de lo socialmente correcto al exceder las normas de conducta marcadas por los códigos de la época.

El enfoque feminista subvierte esta apreciación decimonónica que reduce el crimen merecedor de castigo al acto inmoral cometido por la mujer. De este modo, el análisis se centra, no ya en el adulterio de la esposa y en la venganza del marido, sino en el crimen que se comete contra una mujer a quien no se le permite articular sus deseos y que queda impedida para hacerlo en el futuro. Teniendo en cuenta el significado que el término tiene en la lengua castellana, también se puede hablar aquí de crimen pues, aunque las posibilidades semánticas de la acepción quedan reducidas en la lengua castellana, el acto criminal

Odisea, $\mathrm{n}^{\circ}$ 7, ISSN $1578-3820,2006,159-168$ 
ocurre. Lord Sannox comete un atropello contra el cuerpo de su esposa, a raíz del cual Lady Sannox resulta gravemente herida en un sentido literal. Las consecuencias del crimen también la lesionan en un sentido metafórico, porque la escisión que se le practica en los labios le impedirá disfrutar de una vida artística y sexual plena. Estos son los aspectos que se van a analizar a continuación dentro del contexto social e histórico en el que ocurren los acontecimientos.

Los hechos ficticios narrados en el relato de Conan Doyle suceden en la Inglaterra del último tercio del siglo XIX, época en la que surge en Gran Bretaña la novela sensacionalista y de detectives y en la que irrumpe la figura de la new woman. Es esta una etapa de profunda misoginia y restricción sexual, cuyo origen se halla en la doble influencia de la cultura protestante que determinó el fenómeno de costumbres conocido como el victorianismo (Bornay 1998: 31) y la revitalización de unos severos códigos sexuales y de conducta. En esta época, los sentimientos del hombre hacia la mujer aparecen divididos entre la fascinación y el aborrecimiento. El varón se siente sexualmente seducido por ella; pero al mismo tiempo, en su construcción patriarcal dicotómica en la que sitúa a la mujer como ángel o demonio, desprecia la imagen de la mujer seductora, pues la concibe como origen de todos los males de la humanidad. Estas actitudes misóginas tienen su fundamento en el temor del hombre ante el nuevo papel de la mujer, en la alarma social que crearon los movimientos feministas, en la presencia de la prostitución en la sociedad, en el miedo a las enfermedades venéreas y, por último, en las teorías de carácter antifeminista que autorizaban las actitudes misóginas (Bornay 1998: 16).

Son muchos los escritores que en la última etapa del victorianismo plasman en sus escritos su desazón por el devenir y por las graves consecuencias morales que el largo reinado de la reina Victoria está ejerciendo sobre la sociedad inglesa. Algunos, como Oscar Wilde, critican e ironizan acerca de la hipocresía y la falsedad valiéndose de recursos cómicos propios de la dramaturgia, como la duplicidad de personalidades en los personajes y los juegos de palabras en sus obras de teatro. Otros escritores, como Wilkie Collins y Conan Doyle, intentan concienciar a sus lectores de la necesidad de indagar y desentrañar las realidades sociales y la inmoralidad que subyace bajo esa espesa capa de falso bienestar, aparente normalidad y autocomplacencia que había creado el victorianismo. Para ello se valen de recursos que buscan llamar la atención del público lector. Wilkie Collins, considerado el padre de la novela de detectives inglesa, lo logra mediante la sensación y el asombro; Conan Doyle dirige a los lectores por el camino de la investigación incitándoles a encontrar los auténticos significados de los misterios policiales. Estos autores denuncian mediante estos recursos - a veces sensacionalistas, a veces detectivescoslas miserias sociales, la desilusión y el desencanto por unas promesas de prosperidad inalcanzables. En sus escritos llaman la atención sobre la falta de ética reinante tanto en el ámbito nacional como internacional, pues la Inglaterra de la revolución industrial y el imperio británico generaban riquezas que acentuaban aún más las diferencias de las clases constituyentes de las sociedades donde los británicos estaban establecidos. A esto se debe de añadir que en el ámbito internacional, el Imperio Británico empezaba a mostrar signos de su debilidad ética. La sociedad victoriana llevó a las colonias su doble moral, erigiéndose en un ejemplo a seguir por los distintos grupos étnicos de las sociedades colonizadas. 
Ello no era óbice para arrasar sus legados culturales, las lenguas, religiones y modos políticos de los pueblos, dejando al mismo tiempo al descubierto la inadecuación de sus modelos en unas sociedades que, sorprendidas por la subordinación impuesta, no tardaron en reivindicar y luchar por conseguir de nuevo sus libertades a lo largo del siglo XX.

En la Inglaterra del último tercio de siglo se concedía al matrimonio gran importancia. Las relaciones aparentaban ser correctas en el plano familiar, las mujeres casadas se comportaban como ángeles del hogar y la frase morals and manners se convirtió en señera de la cultura anglosajona decimonónica. Evidentemente, no todas las mujeres estaban casadas ni eran burguesas. Otros grupos de mujeres los formaban las trabajadoras, que al ser de clase social baja estaban invisibilizadas y ausentes de los cánones de conducta impuestos. Estaban también las mujeres mundanas, las femmes fatales por excelencia pues seducían a los hombres y los inducían al pecado. Las mujeres seductoras no se podían invisibilizar porque formaban parte de la vida social de la que disfrutaban los hombres, solteros y casados, y su presencia se consideraba una distracción para los varones, llegando a formar parte de la vida social, de lo que se consideraba "morals and manners." En lo referente a la prostitución, se conocía su existencia y su amplia presencia en la vida de los hombres y no se permitía que llegara a incomodar la vida de las familias. Las prostitutas eran conscientes de la fascinación que despertaban entre los varones, pero también sabían cuáles eran sus limitaciones sociales y quedaban (auto)excluidas de la institución matrimonial.

La normalidad doméstica como constructo social, en cambio, sí se vio alterada y amenazada por la aparición de la figura de la new woman. Con este apelativo se reconocía a las mujeres activistas y trabajadoras profesionales que por su concienciación de clase y género hicieron frente a la sociedad patriarcal de la época. Ellas eran las encargadas de demandar mayores espacios y responsabilidades diferentes de las que asumían las mujeres de la época, las que solicitaban desempeñar tareas públicas y un trato de igualdad al de sus congéneres masculinos y las que despertaban las conciencias de las demás mujeres. En suma, frente a la pasividad de los "ángeles del hogar" otras mujeres estaban empezando a desplegar un poder y a reclamar unos espacios propios que alarmaban al patriarcado. Estos intentos de articulación personal constituían una amenaza y motivaron al protagonista del relato a llevar a cabo su crimen.

Los códigos de conducta que constituyen las "morals and manners" son la herramienta de la que disponen los intelectuales de la época para transgredir, subvertir y denunciar las situaciones de abuso y desamparo social que están teniendo lugar y que impiden que la sociedad inglesa evolucione dejando atrás falsedades e hipocresías. En "El caso de Lady Sannox", Conan Doyle muestra su rechazo valiéndose de una trama de "capa y espada" en la que Lord Sannox descubre que su mujer tiene por amante al famoso cirujano Douglas Stone y urde un plan de venganza sobre ellos dos. Stone es llamado para operar urgentemente a una mujer turca, que no es otra que Lady Sannox, quien ha resultado casualmente herida en los labios por una daga envenenada. El veneno actúa con rapidez y el cirujano ha de operar sin demora haciendo un corte en la boca de la mujer herida. El rostro de Lady Sannox está cubierto, pues las costumbres culturales del falso matrimonio turco así lo dictan. No es de extrañar que esta operación tenga lugar sin un motivo que urja a su realización, pues se trata de operar a una mujer de otra cultura, con toda la autoridad colonial que esto conlleva, máxime teniendo en cuenta el aspecto económico de la opera-

Odisea, $\mathrm{n}^{\circ} 7$, ISSN 1578-3820, 2006, 159-168 
ción que tanto interesa a Stone. Sólo cuando se ha llevado a cabo la ablación descubrirá Stone que tanto él como su amante han sido burlados y han sido víctimas de la venganza tramada por Lord Sannox para impedir así que la pareja continúe su relación adúltera.

El relato sigue el orden tripartito clásico y, de acuerdo con esto, aparece la contextualización social de la época con su pesada y espesa capa de falsa moralidad y buena conducta al presentar a los personajes y el ámbito social al que pertenecen en la primera parte del texto. Así se introduce a Lord Sannox como un personaje aburrido que ha retirado del teatro a una actriz para convertirla en su esposa. Esta redención de Lady Sannox para la vida matrimonial convierte al marido en su salvador, lo que le proporciona la autoridad necesaria para ejercer control sobre la vida de su esposa y dotar a ésta de honorabilidad, pues como dice Bornay, “ la institución matrimonial nunca había sido tan respetada como entonces" (1998: 53). Este respeto y enaltecimiento de la institución matrimonial tiene una segunda lectura. No se trata sólo del respeto que inspira la mujer casada sino del respeto que se le debe al conyuge, dejando implícita la idea de que la esposa es propiedad del marido. Por ello, y también porque se creía que ellas eran el origen de los males del mundo y quienes inducían a pecar, se les imponían a las mujeres unos códigos de conducta proteccionistas y sumamente reductores que marcaban su subordinación. Estas normas eran más exigentes con ellas que con ellos, y más con las mujeres burguesas que con las de baja extracción social. De acuerdo con estos paradigmas victorianos, la figura patriarcal de Lord Sannox pasó de la fascinación por la mujer mundana que conoció en el teatro al aborrecimiento cuando descubre que ella no cumple con el modelo de esposa.

El segundo personaje de la trama argumental es Douglas Stone, un famoso y vanidoso cirujano que necesita ampliar su círculo profesional y económico para hacer frente a los gastos superfluos que soporta. La tercera figura en esta estructura triangular es la protagonista del relato, Lady Sannox. Es éste un personaje plano que no va a poder emprender ninguna acción que la convierta en sujeto, limitándose a ser un objeto a manos de su marido y de su amante. Lady Sannox, por su pertenencia al mundo del espectáculo en su vida pasada, encarna los vicios y las consecuencias fatales que imprimen a la sociedad las mujeres mundanas, antítesis del modelo de virtud que deben de cumplir las esposas victorianas.

Es muy importante para el desarrollo del relato y también para el análisis de género la actividad artística del personaje femenino, pues por su profesión en los escenarios y en los vaudevilles representa el arquetipo de la mujer seductora y reproduce el modelo de la Eva bíblica, opuesto al sumiso y abnegado de la Virgen María. El ideal mariano debería de haber sido el ejemplo a seguir por Lady Sannox, ahora reconvertida en un "ángel del hogar" por su status de mujer casada con el que la sociedad premiaba a sus mujeres y con el que pretendía su subordinación. Como dice Higonnet, "[se] organizaba la feminidad en torno a dos polos opuestos: uno normal, ordenado, tranquilizador, y el otro desviado, peligroso y seductor, de un lado la domesticidad respetuosa; del otro lado, prostitutas, profesionales, activistas y mujeres trabajadoras" (1992: 273).

Las actrices de teatro, por su independencia económica, por trasmitir imágenes de mujeres que, en líneas generales, se alejaban del modelo impuesto por la autoridad patriarcal, por su falta de vida doméstica y por la incompatibilidad que suponía en aquella época 
tener una vida familiar y profesional, quedaban enmarcadas en el grupo de las seductoras, de aquellas que representaban un peligro social: "las mujeres del mundo de la escena medraban gracias a una suerte de exhibicionismo creciente (...) las actrices hipnotizaban tanto a los públicos masculinos como femeninos del mundo occidental y tras su estela surgía una imaginería popular que contribuía a difundir su fama tanto como las apariciones reales en los escenarios" (Higonnet 1992: 290).

También para Cortés, en su ensayo Orden y caos. Un estudio cultural sobre lo monstruoso en el arte, a finales del siglo XIX, con el simbolismo, cobra un crecimiento espectacular el arquetipo de mujer ardiente y cruel, hermosa y depravada, tanto entre los artistas pictóricos como entre los literarios. Teniendo en cuenta el peligro que entraña la divulgación de estos modelos de seducción, no es de extrañar entonces el interés del patriarcado en general y de Lord Sannox en particular, por domeñar y castigar este tipo de actitudes, que unido a la fuerza imparable que desplegaba la new woman, tanto daño podían hacer a las mujeres virtuosas y al orden jerárquico establecido históricamente.

La contextualización social del planteamiento da paso en segundo lugar al nudo de la historia, que acontece en una noche de ambientación gótica. Este recurso incide en la crítica que Doyle desea hacer sobre la Inglaterra victoriana. En especial acerca de la posición de sumisión e impotencia en la que se encuentra Lady Sannox como mujer. A lo largo de todo el siglo XIX las novelistas habían utilizado elementos góticos ${ }^{1}$ para llamar la atención sobre la falta de espacio y la ansiedad que esto les producía; desde Ann Radcliffe hasta Charlotte Brontë y Emily Brontë la utilización de estos recursos refleja su disconformidad, su falta de poder y el temor que les suscita habitar en lugares extraños e incompresibles. En The Madwoman in the Attic, Gilbert y Gubar analizan en profundidad a las novelistas victorianas y sus personajes llamando la atención sobre los aspectos relacionados con los escenarios de sus obras; cómo en su mayoría tras las descripciones de los ambientes en los que tienen lugar las historias se esconden otros significados que indican hasta que punto las protagonistas de las historias están atrapadas en la maraña social de la época: "for instance, heroines who characteristically inhabit mysteriously intricate or uncomfortably stifling houses are often seen as captured, fettered, trapped, even buried alive" (1979: 83).

La ambientación gótica para situar los hechos criminales de esta historia sirve para llamar la atención de los lectores acerca de la inadecuación y la falta de espacios, pues limitan las actividades de los hombres y sobre todo de las mujeres, de Lady Sannox en este caso particular. Marion Dawson, nombre de soltera de la protagonista, queda atrapada por su matrimonio con Lord Sannox en la telaraña social que la Inglaterra nobiliaria de la reina Victoria creaba a su alrededor. La brevedad del relato impide a Doyle ampliar aspectos de la vida de casada de Marion Dawson aunque sí sugiere, a través de las pinceladas con las que describe a los personajes, algunos rasgos que reflejan las especificidades de su matrimonio: "en el escenario de ese teatro conoció a Miss Dawson, a la que ofreció su mano, su título y la tercera parte de un condado"2 (Doyle 2004: 2). En otros momentos se describen

\footnotetext{
1 Ellen Moers acuñó el término de "Female Gothic" para definir esta situación de opresión y confinamiento en la literatura de mujeres del siglo XIX en su obra Literary Women. The Great Writers. (Ellen Moers 1977: 90-112)

2 Las referencias a "The Case of Lady Sannox" han sido extraídas de la traducción realizada por Luis López Nieves para Ciudad Seva. http://www.ciudadseva.com (pp. 1-9)
}

Odisea, $\mathrm{n}^{\circ} 7$, ISSN 1578-3820, 2006, 159-168 
las actividades que lleva a cabo su marido. "era hombre tranquilo, callado, sin color, de labios delgados y párpados voluminosos, muy aficionado a la jardinería y dominado completamente por inclinaciones hogareñas" (2004: 2). Por medio de estas líneas Doyle da las pautas de cómo la posición económica y social de Lord Sannox es un indicativo de poder hasta convertir a Marion Dawson en un preciado trofeo que el noble inglés desea poseer.

Los hechos ocurren en "una noche de invierno, triste, muy fría y ventosa. Ululaba el viento en las chimeneas y sacudía con estrépito las ventanas" (Doyle 2004: 2), estas referencias climatológicas al tiempo exterior presagian el curso de unos acontecimientos desagradables y constituyen una referencia simbólica a la época, pues el ulular del viento que intenta colarse por los resquicios de las ventanas es la metáfora o fisura que nos adentra en el subtexto y permite hacer una lectura crítica que va más allá del cuento de terror doyliano. No sería éste el único intelectual que aludiera a la climatología desapacible para hacer llegar a los lectores el pesimismo que les embargaba. ${ }^{3}$ Así mismo, las palabras con las que Moers define el gótico femenino, cuando habla de heroinas que característicamente habitan en casas misteriosamente laberínticas o incómodamente rígidas y que aparecen a menudo prisioneras, encadenadas, atrapadas, incluso enterradas vivas, tienen su réplica en la explicación que se da de la casa de la mujer turca a quien Douglas Stone debe de salvar:

[de] aspecto ruin en una calle sórdida y estrecha,... [Douglas] Stone avanzó por el estrecho pasillo mirando con sorpresa en torno suyo... no vió otra cosa que gruesas capas de polvo y tupidas orlas de telarañas por todas partes. Sus firmes pisadas resonaban con fuerza por toda la casa en silencio, mientras subía detrás de la anciana por la tortuosa escalera. No había alfombra.

El dormitorio estaba en el segundo descansillo. Douglas Stone entró en él detrás de la anciana, y seguido inmediatamente por el mercader. Allí por lo menos había muebles, incluso con exceso. Se veía en el suelo un revoltijo y en los rincones, verdaderas pilas de vitrinas turcas, mesas incrustadas, cotas de malla, pipas de formas extrañas y armas grotescas. (Doyle 2004: 7)

La definición que David Lodge da de metonimia y metáfora "metaphor juggles with selection and substitution; metonymy juggles with combination and context" (1986: 11) crea unos significados que van más allá de lo meramente denotativo para crear una interpretación metafórica de la falta de espacio y las circunstancias en las que se hallaban las mujeres de la época. Las referencias a las calles y al interior de la casa, sin apenas luz, míseras y estrechas, sinuosas en su recorrido, señalan la situación de opresión y la ausencia de posibilidades en la que se encontraban las esposas victorianas, las calles y las escaleras estrechas y sinuosas se relacionan con las limitaciones y el largo camino que les queda por recorrer. Las alusiones a las gruesas capas de polvo remiten a una sociedad enquistada e inamovible. Las tupidas orlas de telarañas sugieren el modo con el que el victorianismo atrapaba a las mujeres, preparándolas para una engalanada vida matrimonial que las redu-

\footnotetext{
3 Virginia Woolf en Orlando hace una descripción del aspecto tenebroso del victorianismo cuando Orlando anuncia el comienzo del siglo XIX.
} 
cía a meras reproductoras del modelo de virtud que el patriarcado históricamente había difundido y las destruía para ejercer funciones en la vida pública.

Stone ha de avanzar hasta el segundo piso del edificio, por unos intrincados pasillos, para encontrarse a una mujer, prisionera de su época y de su casa: el desorden de la habitación, la profusión de muebles y objetos varios remiten simbólicamente a los impedimentos que tiene Lady Sannox para escapar de la tupida maraña social victoriana. Estos elementos góticos, que dan fuerza al relato y denuncian la situación de horror de las mujeres decimonónicas, sirven para que el público lector no se quede en el nivel superficial del texto en el que se narran los hechos, sino que busque signos como estos que permiten la deconstrucción del relato y hacer una reinterpretación del mismo.

La tercera parte marca el punto climático de la historia: el crimen si se observa desde el punto de vista feminista y el castigo si se hace desde la perspectiva patriarcal. Stone se muestra contrario a realizar la operación en la que se debe de cortar el labio inferior al personaje femenino. Accede a ello ante la insistencia de Lord Sannox, pensando también en el beneficio económico, tan necesario para mantener su status social.

La perfecta estructura del relato adentra al público lector por las escaleras sinuosas del victorianismo, pues a la contextualización histórico social y temporal que denuncia la situación de desencanto del último tercio del reinado de la reina Victoria en la primera parte del relato, le sigue la descripción de los hechos, centrándose la crítica de Doyle en las condiciones de sumisión y enclaustramiento social y familiar y en la falta de espacio y la inadecuación del mismo que impedía a las mujeres su articulación. Así logra el público lector llegar al clímax del relato y a la esencia del problema del patriarcado decimonónico: el control de la sexualidad de la mujer.

La única vida sexual que le estaba permitida a la mujer victoriana era la que conducía a satisfacer el placer del hombre y la que tenía una finalidad reproductora. A Lady Sannox, por tanto, se le suponía una vida matrimonial tranquila, acorde con el carácter de Lord Sannox, amante de su casa y de su jardín. Al mantener una relación adúltera, Marion transgrede las normas oficiales de la sexualidad victoriana y pasa a convertirse en un ser amenazador a quien su marido aborrece. En este contexto patriarcal, las mujeres, por la fascinación que despiertan en los hombres, se convierten en un peligro para éstos y constituyen la amenaza de la castración pues sus dotes de seducción pueden hacer perder a los hombres el dominio y el control patriarcal históricamente adquirido. Para evitar que esto ocurra Lord Sannox ha de darle una lección moralizante a su esposa, que sirva de ejemplo a ella y a toda la sociedad. Así, de femme fatale seductora, pasará a ser una mujer retirada de la vida mundana, convirtiéndose en ejemplo edificante para el victorianismo, pero en la víctima de una agresión sexual para la crítica feminista.

Para Elizabeth Wright, "Feminist literary and art criticism, and feminist film criticism have a particular investment in the exploration of sign systems in order to discover how woman is signified, how she came to be positioned in preordained social roles" (1995: 173). En esta exploración de los signos queda manifiesta la gravedad del crimen que se comete contra Marion Dawson y la pasividad de la que es víctima; sufrirá la violencia en su propio cuerpo sin tener capacidad para defenderse. En el diálogo que mantienen Stone y Lord Sannox queda patente su indefensión:

Odisea, $\mathrm{n}^{\circ} 7$, ISSN 1578-3820, 2006, 159-168 
— Le ha dado usted una dosis de opio muy fuerte.

- Sí, ha sido bastante buena.

El cirujano volvió a contemplar los ojos negros que lo miraban fijamente. Estaban apagados y sin brillo, pero pudo advertir que aparecía en ellos una lucecita de vida, y que le temblaban los labios. (Doyle 2004: 8)

Su estado de semiinconsciencia y su mirada apagada y sin brillo remiten a su inarticulación y a la imposibilidad de abandonar la urdimbre tejida a su alrededor. La actriz Marion Dawson convertida en Lady Sannox no tiene ya capacidad de acción. La vida de mujer casada la reduce como persona a ser simple reproductora del modelo mariano del cristianismo. Su adulterio transgrede las normas y codigos de conducta del matrimonio, alejándose del ejemplo de virtud que Lord Sannox desea; de ahí que su marido, encarnación jerárquica, deba de castigarla de acuerdo con el "crimen" por ella cometido. El relato llega a su culminación con la operación que ha de realizar Stone sobre su paciente "turca." que, ataviada con un yashmak y un velo, simboliza así su inarticulación y oculta con este disfraz su verdadero yo.

El hecho de que la operación consista en practicar un corte en la boca, en el labio inferior, permite hacer una significación figurada de los órganos sexuales de la mujer. Según esta interpretación, la boca representaría la vulva, el labio inferior remite también al órgano sexual femenino, la daga envenenada o miembro fálico, por tratarse de un adulterio, lleva consigo el veneno a la sociedad. El corte que se practica con ayuda de un forceps ginecológico no deja dudas al respecto; la operación que se le realiza en la boca simboliza la ablación del labio inferior de su vulva: "Sujetó con forceps el labio herido y dando dos rápidos cortes se llevó una ancha tira de carne en forma de V" (Doyle 2004: 8). El trozo de tejido que se le corta en la operación la incapacita para obtener placer en la relación sexual y el estigma en forma de $\mathrm{V}$, remite al público lector a varios significados, ya sea vagina, ya sea vulva, la finalidad del castigo es ejemplarizante y muestra la superioridad avasalladora del patriarcado. Hay un tercer significado, la marcación de la V puede también aludir al victorianismo, convirtiéndose en una especie de divisa de la época en la que se le inflige el castigo ${ }^{4}$.

Lady Sannox, repudiada por su marido, pierde su status nobiliario concedido por su matrimonio con él y se retira de la vida social. Para Lord Sannox, brazo ejecutor del patriarcado, la operación que se le realiza a su esposa se convierte en una lección edificante para la sociedad: "La verdad es -dijo por fin- que esta operación era verdaderamente indispensable para Mary; no física, pero sí moralmente ... Tenía desde hace mucho tiempo el propósito de dar un pequeño ejemplo." (Doyle 2004: 8). Se trata de un castigo ejemplar cuya finalidad es que las mujeres no se atrevan a transgredir la férrea conducta sexual victoriana.

Desde todas las perspectivas, el crimen que se comete contra Marion Dawson es terrible. El personaje no puede volver a sentir placer ni ser amada; tampoco puede ejercer su profesión por lo que queda absolutamente inarticulada. De acuerdo con la explicación

${ }^{4}$ No sería este el único ejemplo en la literatura. El estigma con el que se castiga el adulterio en la mujer tiene su antecedente en la A de adulterio que Hester Prynne lleva bordada sobre el pecho en The Scarlet Letter de Nathaniel Hawthorne.

Odisea, $\mathrm{n}^{\circ}$ 7, ISSN 1578-3820, 2006, 159-168 
figurada de su ablación, ésta le incapacita para desear y gozar en sus relaciones amorosas. Como actriz de teatro, y sin recurrir a la explicación metafórica de esta castración, la amputación del labio inferior la imposibilita para el escenario y para la vida diaria. Su rostro queda desfigurado con la incisión que se le practica en la boca y la ancha tira de carne que se le amputa le impedirá declamar y recitar escenas en el mundo teatral; de igual modo, tampoco podrá conversar con las personas de su entorno ni articular su discurso.

En este análisis del relato de Doyle se habla de crimen y castigo. Para la época victoriana se trata de un crimen el hecho de que una mujer casada se salga de lo normativo y se sitúe en los márgenes de la sociedad y mantenga relaciones ilícitas con otro varón, de ahí que se le inflija un castigo aleccionador. Para la crítica feminista, es mucho más importante la desfiguración que sufre Marion Dawson y la fragmentación de la que es objeto. Lord Sannox, representante de la nobleza inglesa, hace uso de su superioridad física y "moral". El crimen con el que castiga a su esposa es un intento desesperado de la ideología victoriana por impedir a las mujeres avanzar en sus logros y articular sus deseos.

\section{REFERENCIAS BIBLIOGRÁFICAS}

Bornay, E. 1998. Las hijas de Lilith. Madrid: Cátedra. Ensayos Arte.

CoRTES, J. M. 1997. El orden y el caos. El lado obscuro del arte. Barcelona: Anagrama.

Doyle, A.C. 1893. "The Case of Lady Sannox" Round the Red Lamp. Trad. Luis LóPEZ NiEves. "El caso de Lady Sannox". San Juan de Puerto Rico: Biblioteca digital Ciudad Seva. 24 de marzo de 2004.<http://ciudadseva.com>.

Gilbert, S. \& S. Gubar. 1984 (1979). The Madwoman in the Attic. New Haven \& London: Yale University Press.

Higonnet, A. 1993 (1990). "Las mujeres y las imágenes. Apariencia, tiempo libro y subsistencia." Historia de las mujeres IV. Eds. G. Duby y M. Perrot. Barcelona: Círculo de lectores. 271-297

Lodge, D. 1986. Working with Structuralism. London: Ark Paperback.

MoErs, E. 1977. Literary Women. The Great Writers. New York: Anchor Press.

Moliner, M. 1990. Diccionario de uso del español. Madrid: Editorial Gredos.

Rins, S. 2001. La emoción sin nombre. Col. Versión original. Cáceres: Re Bross.

Todorov, T. 1988 (1966). “The Typology of Detective Fiction.” Ed. D. LodgE Modern Criticism and Theory. London \& New York: Longman. 157-166.

VV.AA. 1988 (1987). Collins Cobuild English Language Dictionary. London \& Glasgow: Collins.

VV.AA. 1970. Diccionario de la Lengua Española de la Real Academia Española. Madrid: Decimonovena ed. Espasa Calpe.

Wright, E. 1995 (1968). Psychoanalytic Criticism. Cambridge: Polity Press. 